\title{
COVID-19-related strokes in adults below 55 years of age: a case series
}

\author{
Farzad Ashrafi ${ }^{1}$ (D) Alireza Zali $^{1} \cdot$ Davood Ommi $^{1} \cdot$ Mehri Salari $^{1} \cdot$ Alireza Fatemi $^{1} \cdot$ Mehran Arab-Ahmadi $^{2}$. \\ Behdad Behnam ${ }^{3} \cdot$ Arash Azhideh $^{1} \cdot$ Mohammad Vahidi $^{1} \cdot$ Maryam Yousefi-Asl $^{1} \cdot$ Reza Jalili khoshnood $^{1}$. \\ Soroor Advani ${ }^{1}$
}

Received: 30 May 2020 / Accepted: 16 June 2020 / Published online: 24 June 2020

(C) Fondazione Società Italiana di Neurologia 2020

\begin{abstract}
Background Coronavirus infection is a novel respiratory disease affecting people across the world. Although the majority of patients present with fever, dyspnea, cough, or myalgia, various signs and symptoms have been reported for this disease. Recently, neurological symptoms have been noticed in patients with COVID-19 with unknown etiology. However, the occurrence of strokes in young and middle aged patients with COVID-19 is not fully explained.

Methods In this series, six patients younger than 55 years of age with diagnosis of stroke and a confirmed diagnosis of COVID19 were evaluated for symptoms, lab data, imaging findings, and outcomes from March 2020 to the end of April 2020 from all stroke cases in a tertiary academic hospital. Patients older than 55 and all others who had evidence of cardiac abnormalities (arrhythmia/valvular) were excluded.

Results Fever, myalgia, cough, and dyspnea were the most common clinical symptoms noted in $66.66 \%(4 / 6), 66.66 \%(4 / 6)$, $50 \%(3 / 6)$, and 50\% (3/6) of the patients, respectively. The mean \pm standard deviation (SD) of National Institutes of Health Stroke Scale (NIHSS) for the patient was $10.16 \pm 7.13$ (ranged 5-24). The most involved area was middle cerebral artery (MCA) (five in MCA versus one in basal ganglia) and the majority of our patients had a low lung involvement score (mean \pm SD: 13.16 \pm 6.49 out of 24). Finally, one patient was deceased and rest discharged.

Conclusion Stroke may be unrelated to age and the extent of lung involvement. However, different factors may play roles in cooccurrence of stroke and COVID-19 and its outcome. Future studies with long-term follow-up and more cases are needed to assess prognostic factors.
\end{abstract}

Keywords COVID-19 $\cdot$ Coronavirus $\cdot$ Stroke $\cdot$ Neurological manifestation

\section{Background}

Coronavirus infection is a novel, highly contagious respiratory disease caused by SARS-CoV-2 affecting people across the

Farzad Ashrafi

farzad.ashrafi@gmail.com

1 Functional Neurosurgery Research Center, Shohada Tajrish Neurosurgical Center of Excellence, Shahid Beheshti University of Medical Sciences, Tehran, Iran

2 Advanced Diagnostic and Interventional Radiology Research Center, Tehran University of Medical Sciences, Tehran, Iran

3 Department of Internal Medicine, Firoozgar Hospital, Iran University of Medical Sciences, Tehran, Iran world [1]. The most frequent symptoms are fever, dyspnea, cough, or myalgia [2]. Although various signs and symptoms have been reported for this disease, some of them are not clear yet. It may involve both the central nervous system (CNS) and peripheral nervous system (PNS). In this regard, headache, vertigo, cognitive impairment, epilepsy, acute cerebrovascular event ataxia, ageusia, anosmia, neuralgia, and Guillain-Barre syndrome are some of the reported neurological manifestations [3-5].

According to previous reports, viral infections including COVID-19 may play a role as a potential risk factor in developing cerebrovascular diseases such as acute ischemic stroke especially in patients with the severe form of infection [6].

The role of COVID-19 in initiating proinflammatory and hypercoagulable state has been well described [7]. Also, because of inflammation, hypoxia, immobilization, and diffuse intravascular coagulation (DIC), patients with COVID-19 are 
Table 1 Demographic, clinical features, and outcome of the patients

\begin{tabular}{|c|c|c|c|c|c|c|c|c|c|}
\hline $\begin{array}{l}\text { Patient } \\
\text { No. }\end{array}$ & $\begin{array}{l}\text { Age, } \\
\text { year/gender }\end{array}$ & Comorbidities & Fever & $\begin{array}{l}\text { COVID-19 } \\
\text { symptoms }\end{array}$ & Stroke symptoms & $\begin{array}{l}\mathrm{O}_{2} \text { sat on } \\
\text { room air } \\
(\%)\end{array}$ & NIHSS & $\begin{array}{l}\text { Hospital } \\
\text { length of } \\
\text { stay }\end{array}$ & Outcome \\
\hline 1 & $33 / \mathrm{F}$ & - & + & lethargy & $\begin{array}{l}\text { Reduced level of consciousness, } \\
\text { global aphasia, right side } \\
\text { hemiplegia }\end{array}$ & 85 & 24 & 5 & Death \\
\hline 2 & $39 / \mathrm{M}$ & - & + & $\begin{array}{l}\text { Cough, } \\
\text { headache, } \\
\text { myalgia, } \\
\text { dyspnea }\end{array}$ & $\begin{array}{l}\text { Left side hemiparesis, homonymous } \\
\text { hemianopia, sensory deficit, } \\
\text { dysarthria }\end{array}$ & 89 & 9 & 10 & Discharged \\
\hline 3 & $49 / \mathrm{F}$ & HTN & - & Myalgia & $\begin{array}{l}\text { Left side hemiplagia,heminimous } \\
\text { hemianopia, dysarthera }\end{array}$ & 90 & 11 & 14 & Discharged \\
\hline 4 & $40 / \mathrm{M}$ & - & - & $\begin{array}{l}\text { Myalgia, } \\
\text { dyspnea }\end{array}$ & Right side hemiparesis, dysarthera & 89 & 6 & 7 & Discharged \\
\hline 5 & $53 / \mathrm{M}$ & HTN & + & Cough, diarrhea & Left side hemiparesis, dysarthria & 91 & 5 & 7 & Discharged \\
\hline 6 & $47 / \mathrm{F}$ & $\mathrm{DM} / \mathrm{HTN}$ & + & $\begin{array}{l}\text { Myalgia, cough } \\
\text { and dyspnea }\end{array}$ & Right side hemiparesis, dysarthria & 82 & 6 & 9 & Discharged \\
\hline
\end{tabular}

$F$ female, $M$ male, HTN hypertension, NIHHS National Institutes of Health Stroke Scale

at a higher risk of both venous and arterial thromboembolic events. Recently, heparin has been associated with lower mortality in severe cases of COVID-19 or with elevated D-dimer [8]. However, the mechanism and its pathology are rarely understood.

There are currently limited data about patient's characteristics, extent of lung involvement, and other factors in the patients with stroke and COVID-19. This series is presented to point out to physicians to keep cerebrovascular attacks in mind as an important condition in patients with COVID-19 that may need urgent interventions. In addition, the other aim of this study was to show coronavirus as a causative agent for stroke which is unrelated to age and lung involvement extension.

\section{Cases}

Our cases were patients presented to our academic tertiary hospital, stroke unit, with clinical symptoms of stroke from
Table 2 Summary of baseline laboratory findings

\begin{tabular}{|c|c|c|c|c|c|c|c|}
\hline & 1 & 2 & 3 & 4 & 5 & 6 & $\begin{array}{l}\text { Summery (mean } \pm \\
\text { SD) }\end{array}$ \\
\hline $\begin{array}{l}\text { White blood cell } \\
\text { count }\end{array}$ & 8000 & 5500 & 8700 & 7400 & 4500 & 9000 & $7183.33 \pm 1808.22$ \\
\hline Neutrophil count & 5600 & 4700 & 6960 & 6364 & 2925 & 7650 & $5699.83 \pm 1705.38$ \\
\hline Lymphocyte count & 2400 & 800 & 1392 & 888 & 1575 & 1350 & $1400.83 \pm 575.38$ \\
\hline $\begin{array}{l}\text { Hemoglobin } \\
\text { (mg/dL) }\end{array}$ & 9.8 & 10.7 & 11.8 & 16.8 & 15.8 & 12.5 & $12.89 \pm 2.80$ \\
\hline Platelet $\times 10^{3}$ & 305 & 183 & 146 & 223 & 101 & 210 & $194.66 \pm 69.98$ \\
\hline $\mathrm{CRP}(\mathrm{mg} / \mathrm{L})$ & 24 & 12 & 27 & 5 & 12 & 10 & $15.0 \pm 8.57$ \\
\hline $\mathrm{LDH}(\mu / \mathrm{L})$ & 345 & 347 & 1393 & 356 & 430 & 460 & $555.16 \pm 413.24$ \\
\hline $\mathrm{Cr}(\mathrm{mg} / \mathrm{dL})$ & 0.8 & 0.8 & 1.09 & 1.2 & 1.2 & 1.04 & $1.02 \pm 0.18$ \\
\hline $\operatorname{AST}(\mu / \mathrm{L})$ & 16 & 14 & 94 & 21 & 17 & 11 & $28.83 \pm 32.09$ \\
\hline $\operatorname{ALT}(\mu / \mathrm{L})$ & 15 & 11 & 106 & 13 & 10 & 14 & $28.16 \pm 38.17$ \\
\hline $\operatorname{ALP}(\mu / \mathrm{L})$ & 143 & 134 & 415 & 209 & 204 & 162 & $211.16 \pm 104.52$ \\
\hline Albumin (g/dL) & 5.01 & 4.8 & 3.9 & 4.8 & 4.1 & 4.3 & $4.48 \pm 0.44$ \\
\hline D-Dimer & 728 & 810 & 954 & 682 & 600 & 1293 & $844.50 \pm 250.63$ \\
\hline PT (s) & 13 & 13 & 13 & 14 & 13 & 14 & $13.33 \pm 0.51$ \\
\hline PTT (s) & 28 & 40 & 30 & 40 & 38 & 30 & $34.33 \pm 5.57$ \\
\hline INR & 1 & 1 & 1 & 1.1 & 1 & 1.1 & $1.03 \pm 0.51$ \\
\hline
\end{tabular}

$C R P$ C-reactive protein, $L D H$ lactic acid dehydrogenase, $C r$ creatinine, $B U N$ blood urea nitrogen, $A S T$ aspartate transaminase, $A L T$ alanine transaminase, $A L P$ alkaline phosphatase, $P T$ prothrombin time, $P T T$ partial thromboplastin time, INR international normalized ratio 
Fig. 1 Thirty-three-year-old female with fever and reduced level of consciuosness who had a history of exposure to known case of COVID-19 in his family. a Left MCA territory hypodencities in brain CT scan (a) and increased signal of cortex, white matter, head of left caudete, lentiform nulclei, and anterior horn of internal capsule in T2 and FLAIR brain MRI sequences (c, d), in favor of subacute infarct. b Small subpleuroal consodiation in superior segment of right lung inferior lobe highly suggestive for COVID-19

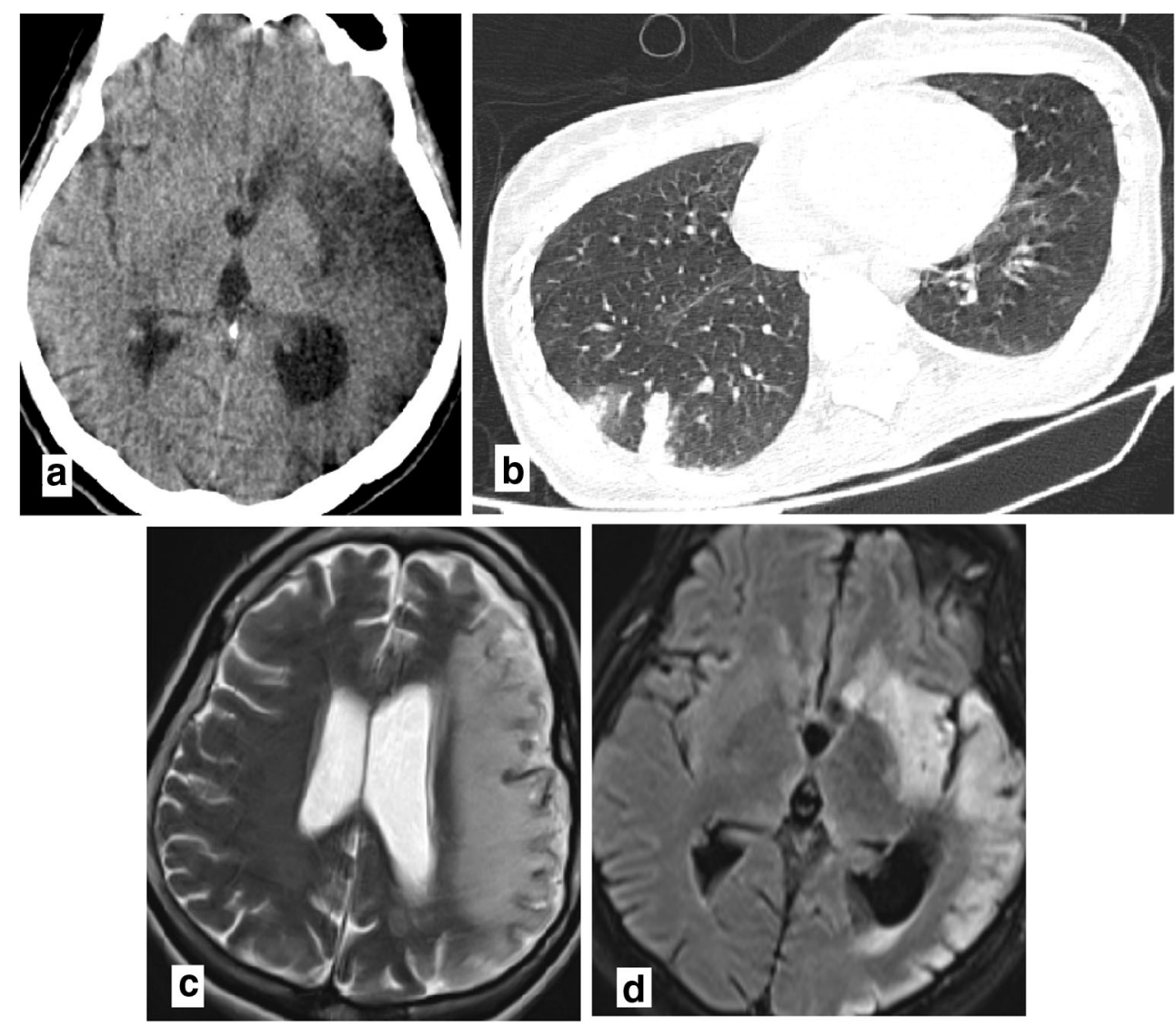

March 2020 to the end of April 2020. We exclude patients older than 55 and all others who had evidence of cardiac arrhythmia or cardiac valvular disease based on electrocardiogram, transthoracic and transesophageal echocardiography, and 24-h Holter monitoring findings. Although all patients primarily presented with neurological symptoms, the diagnosis of COVID-19 was made based on positive nasopharyngeal polymerase chain reaction (PCR) and lung CT scan except one of them who was a 49-year-old female with previous diagnosis of COVID-19 who was discharged from another hospital and admitted to our stroke unit 5 days later.
The mean age ( \pm standard deviation [SD]) was $43.5 \pm 7.42$ (range 33-53 years) and half of them were male. COVID-19 symptoms were evaluated by history taking except one of our cases (33 years old female) who presented altered levels of consciousness and fever. The most common sign and symptom of COVID-19 were fever (four/six), myalgia (four/six), cough (three/six), and dyspnea (three/six). All patients had $\mathrm{O}_{2}$ saturation below $92 \%$ in room air while none of them were hypotensive. Half of the patients had history of hypertension and one case had diabetes mellitus.
Fig. 2 Thirty-nine-year-old male with fever, cough, and mylgia from 6 days before presentation and sudden onset of left side hemiplegia and dysartheria. a Hypodensities in right MCA branch territorty suggestive of subacute infarct. b Diffused ground glass opacities with interalobular septal thickening in superior segment of left lung lower lobes highly suggestive for COVID-19
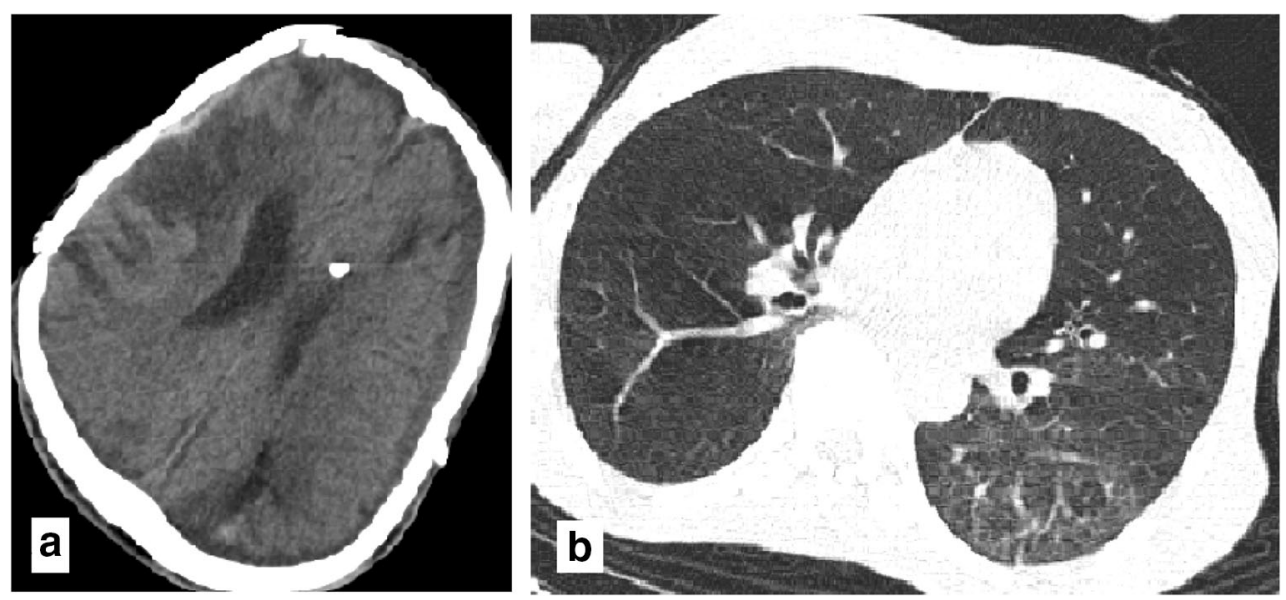
Fig. 3 Forty-nine-year-old female with pervious history of moderate COVID-19 who admitted to our stroke unit with left side hemiplegia, sensory deficiet, and dysarthria. a Wedge-shaped hypodensities in right MCA territory consistent with subacute infarct in brain CT scan. b Diffused peripheral and central consoliadtion patches with crazy paving pattern in some areas consistent with late phase of COVID-19
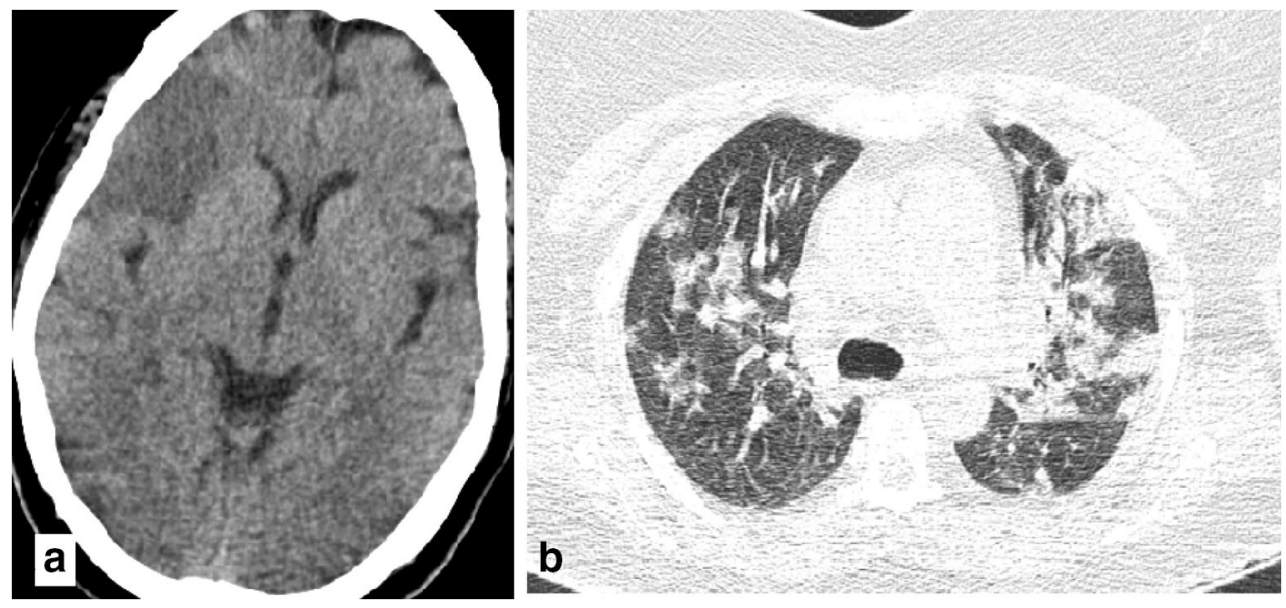

Mean ( \pm standard deviation) of National Institutes of Health Stroke Scale (NIHSS) for the patient was 10.16 \pm 7.13 (ranged 5-24). Detailed clinical features and outcomes of the patients are noted in Table 1. In addition, the initial laboratory findings are shown in Table 2.

All patients underwent imaging studies for stroke and also chest CT scan with low-dose protocol [9]. The initial chest CT scan evaluated for estimation of lung involvement score using zonal involvement percentage method with the maximum

Table 3 Summary of baseline imaging findings

Patient Infarcted area Lung CT scan findings (lung TCCS

No. based on involvement score out of 24) imaging

\begin{tabular}{|c|c|c|c|}
\hline 1 & $\begin{array}{l}\text { Left middle } \\
\quad \text { cerebral } \\
\text { artery } \\
\text { territory }\end{array}$ & $\begin{array}{l}\text { Small subpleuroal } \\
\text { consodiation in right lower } \\
\text { lobes (2) }\end{array}$ & $\begin{array}{r}\text { Flow was not } \\
\text { detected in } \\
\text { Left MCA. }\end{array}$ \\
\hline 2 & $\begin{array}{l}\text { Right middle } \\
\text { cerebral } \\
\text { artery } \\
\text { territory }\end{array}$ & $\begin{array}{l}\text { Ground glass opacities in left } \\
\text { lower lobes ( } 3 \text { ) }\end{array}$ & $\begin{array}{l}\text { Poor temporal } \\
\text { window }\end{array}$ \\
\hline 3 & $\begin{array}{l}\text { Right middle } \\
\text { cerebral } \\
\text { artery } \\
\text { territory }\end{array}$ & $\begin{array}{l}\text { Diffused consoliadtion } \\
\text { patches }(16)\end{array}$ & Normal \\
\hline 4 & $\begin{array}{l}\text { Left middle } \\
\quad \text { cerebral } \\
\text { artery } \\
\text { territory }\end{array}$ & $\begin{array}{l}\text { Bilateral peripheral ground } \\
\text { glass opacities in lower } \\
\text { zones (4) }\end{array}$ & Normal \\
\hline 5 & $\begin{array}{l}\text { Right middle } \\
\text { cerebral } \\
\text { artery } \\
\text { territory }\end{array}$ & $\begin{array}{l}\text { Bilateral peripheral ground } \\
\text { glass opacities in middle } \\
\text { zones }(8)\end{array}$ & Normal \\
\hline 6 & $\begin{array}{r}\text { Left basal } \\
\text { ganglia }\end{array}$ & $\begin{array}{l}\text { Right side lower and middle } \\
\text { zones ground glass with } \\
\text { sub pleural ground glass } \\
\text { opacities in left lower zone } \\
\text { (10) }\end{array}$ & $\begin{array}{l}\text { Poor temporal } \\
\text { window }\end{array}$ \\
\hline
\end{tabular}

TCCS transcranial color-coded duplex ultrasonography, $M C A$ middle cerebral artery score of $24[10]$. The mean score $( \pm \mathrm{SD})$ was $13.16 \pm 6.49$ (ranged 2-16) and bilateral ground glass opacities were the most predominant pattern (Fig. 2).

Brain CT scan findings revealed the stroke territories as follows: right middle cerebral artery (MCA) infarction $(n=3)$, left MCA $(n=2)$, and left basal ganglia infarction $(n=1)$, and the majority of the patients had large vessel stroke. Figures 1, 2, and 3 show brain CT beside lung CT scans of three patients. Our data demonstrated that the majority of our patients had low lung involvement rate while they had more severe conditions based on NIHSS score. Carotid duplex was negative for any significant findings (stenosis, atherosclerotic plaque, or dissection) and results of transcranial color-coded duplex ultrasonography (TCCS) have been summarized in Table 3.

Regarding our national guidelines, all patients were placed on hydroxychloroquine $400 \mathrm{mg}$ stat and lopinavir/ritonavir 400/100 mg twice daily and intravenous antibiotic. In addition, because all the patients were presented to the emergency room $3 \mathrm{~h}$ after their symptom initiation, they were not candidate for thrombolytic therapy so all of them underwent medical treatment with ASA and Plavix for secondary prevention. All patients were followed up to the study endpoint, five patients were discharged; however, one case did not survive.

\section{Discussion}

This series showed the co-occurrence of stroke and COVID19 in adults younger than 55 years of age. To date, there is limited data on the association of COVID-19 and ischemic stroke mechanism, clinical course, prevention, management, and risk stratification.

Valderrama et al. reported a 52-year-old man with COVID19 who presented with sudden onset hemiparesis and aphasia (NIHSS: 20) on his seventh day of treatment and brain CT scan confirmed the diagnosis of stroke in MCA territory. On further work up, they did not find any risk factor for stroke [11]. 
In this study, the majority of our patients (five/six) were not known cases of COVID-19 infection and all of them were admitted to our stroke unit with neurological complaints while Mao et al. reported the occurrence of stroke in approximately $2 \%$ of COVID-19 patients during their admission [12]. In a study by TJ Oxley et al., large-vessel strokes were presented in five COVID-19 cases younger than 50 years old, and unlike our patients, all of them had severe COVID-19 [13].

Avula et al., described acute stroke in four old-aged patients (range 73-88 years) with confirmed diagnosis of COVID-19, while the oldest patient in this study was 53 years old [14].

It seems that factors such as direct virus invasion, inflammatory processes, cytokine release, hypoxemia, hypotension, or vasculitis are possible mechanisms of coronavirus affecting the nervous system.

This is the first study evaluating the association of long involvement extension and stroke severity. In this regard, our cases showed that lung involvement extension may be unrelated to developing a stroke and its severity based on NIHSS. On the other hand, D-Dimer level may play a critical role as a prognostic factor as elevated D-Dimer levels were seen in all of our patients.

Poggiali et al. reported two cases of COVID-19 who complicated with DVT and PE after at least 10 days since their symptoms started [15]. Also, based on a recent study, COVID-19 could be predisposed to venous and arterial thromboembolism leading to diffuse intravascular coagulation, severe inflammation, immobilization, and hypoxia [16].

An investigation on ICU-admitted patients with COVID19 showed that the incidence of thrombotic complications was extremely high (31\%). The study revealed that pharmacological thrombosis prophylaxis is critically important to be added to the treatment regimen of all COVID-19 patients admitted to ICU [16].

\section{Conclusion}

In conclusion, COVID-19 can cause thrombotic complications, hyper-inflammation, and tissue damage, which may increase the risk of ischemic stroke in young and middle aged patients even in early stages and mild forms of COVID-19.

\section{Compliance with ethical standards}

Conflict of interest The authors declare that they have no conflict of interest.

Ethics approval The study protocol was approved by the ethics committee of the Shahid Beheshti University of Medical Sciences (IR.SBMU.RETECH.REC.1399.115).
Informed consent Written informed consents were obtained from patients or their guardian.

\section{References}

1. Guan W-J, Ni Z-Y, Hu Y, Liang W-H, Ou C-Q, He J-X et al (2020) Clinical characteristics of coronavirus disease 2019 in China. N Engl J Med

2. Adhikari SP, Meng S, Wu Y-J, Mao Y-P, Ye R-X, Wang Q-Z et al (2020) Epidemiology, causes, clinical manifestation and diagnosis, prevention and control of coronavirus disease (COVID-19) during the early outbreak period: a scoping review. Infect Dis Poverty 9(1): $1-12$

3. Mao L, Jin H, Wang M, Hu Y, Chen S, He Q, Chang J, Hong C, Zhou Y, Wang D, Miao X, Li Y, Hu B (2020) Neurologic manifestations of hospitalized patients with coronavirus disease 2019 in Wuhan, China. JAMA Neurol 77:683

4. Azhideh A (2020) COVID-19 neurological manifestations. Int Clin Neurosci J 7(2):54

5. Niazkar HR, Zibaee B, Nasimi A, Bahri N The neurological manifestations of COVID-19: a review article

6. Wu Y, Xu X, Chen Z, Duan J, Hashimoto K, Yang L et al (2020) Nervous system involvement after infection with COVID-19 and other coronaviruses. Brain Behav Immun

7. Han H, Yang L, Liu R, Liu F, Wu K-L, Li J et al (2020) Prominent changes in blood coagulation of patients with SARS-CoV-2 infection. Clin Chem Lab Med 1

8. Tang N, Bai H, Chen X, Gong J, Li D, Sun Z (2020) Anticoagulant treatment is associated with decreased mortality in severe coronavirus disease 2019 patients with coagulopathy. J Thromb Haemost

9. Radpour A, Bahrami-Motlagh H, Taaghi MT, Sedaghat A, Karimi MA, Hekmatnia A, Haghighatkhah HR, Sanei-Taheri M, ArabAhmadi M, Azhideh A (2020) COVID-19 evaluation by lowdose high resolution CT scans protocol. Acad Radiol 27:901

10. Zhou S, Wang Y, Zhu T, Xia L. CT features of coronavirus disease 2019 (COVID-19) pneumonia in 62 patients in Wuhan, China. Am J Roentgenol 2020:1-8

11. Valderrama EV, Humbert K, Lord A, Frontera J, Yaghi S (2020) Severe acute respiratory syndrome coronavirus 2 infection and ischemic stroke. Stroke STROKEAHA. 120.030153

12. Mao L, Wang M, Chen S, He Q, Chang J, Hong C, et al. Neurological manifestations of hospitalized patients with COVID-19 in Wuhan, China: a retrospective case series study. 2020

13. Oxley TJ, Mocco J, Majidi S, Kellner CP, Shoirah H, Singh IP et al (2020) Large-vessel stroke as a presenting feature of Covid-19 in the young. N Engl J Med:e60

14. Avula A, Nalleballe K, Narula N, Sapozhnikov S, Dandu V, Toom $\mathrm{S}$ et al (2020) COVID-19 presenting as stroke. Brain Behav Immun

15. Poggiali E, Bastoni D, Ioannilli E, Vercelli A, Magnacavallo A (2017) Deep vein thrombosis and pulmonary embolism: two complications of COVID-19 pneumonia? Eur J Case Rep Intern Med

16. Klok FA, Kruip M, Van der Meer N, Arbous M, Gommers D, Kant $\mathrm{K}$ et al (2020) Confirmation of the high cumulative incidence of thrombotic complications in critically ill ICU patients with COVID19: an updated analysis. Thromb Res

Publisher's note Springer Nature remains neutral with regard to jurisdictional claims in published maps and institutional affiliations. 